\title{
Level of agreement among Latin American glaucoma subspecialists on the diagnosis and treatment of glaucoma: results of an online survey
}

\author{
Nível de concordância entre subespecialistas de glaucoma latino-americanos sobre o diagnóstico \\ e tratamento do glaucoma: resultados de uma pesquisa digital
}

Daniel E. Grigera ${ }^{1}$, Paulo Augusto Arruda Mello², Wilma lelis Barbosa ${ }^{3}$, Javier Fernando Casiraghi ${ }^{4}$, Rodolfo Perez Grossmann ${ }^{5}$, Alejo Peyret ${ }^{6}$

\begin{abstract}
Purpose: The aim of this research was to assess the level of agreement among glaucoma experts in Latin America on key practices related to treatment and diagnosis of glaucoma.

Methods: An online questionnaire was sent to a multinational panel of glaucoma experts. The questionnaire contained 107 statements on the medical treatmen (Part 1) and diagnosis (Part 2) of glaucoma, and was developed in Spanish and translated into English. Agreement was defined as $\geq 70 \%$ of respondents.

Results: Fifty participants from 14 countries completed the questionnaire. For the medical treatment of glaucoma, nearly all respondents ( $98 \%$ or greater) confirmed that medical treatment as first-line therapy is preferred to surgery, prostaglandin analogs are the medication of first choice for primary open-angle glaucoma (POAG), longitudinal monitoring of efficacy should include intraocular pressure, structura and functional status, as well as if patients' quality of life is impaired by the high cost of medication. For the diagnosis of glaucoma section, all respondents confirmed that, after initial examination, gonioscopy should be repeated over time, standard automated perimetry is the most important functional examination for diagnosis and monitoring of primary open-angle glaucoma, central corneal thickness is important in assessment of glaucoma, and computerized imaging tests help in clinical evaluation of optic disc.

Conclusions: This survey shows a high level of agreement on most aspects of glaucoma diagnosis and treatment among Latin American glaucoma experts. Areas of disagreement highlight the need for further evidence or education. These findings will be useful for guiding future efforts to optimize glaucoma practice by clinicians in Latin America.
\end{abstract}

Keywords: Glaucoma/diagnosis; Glaucoma/therapy; Questionnaires; Humans

\section{RESUMO}

Objetivo: Avaliar o nivel de concordância entre os especialistas de glaucoma na América Latina sobre as práticas mais importantes relacionadas ao tratamento e diagnóstico de glaucoma.

Métodos: Um questionário digital foi enviado a um painel multinacional de especialistas em glaucoma. O questionário continha 107 declarações sobre o tratamento médico (Parte 1) e diagnóstico (Parte 2) de glaucoma, efoi desenvolvido em espanhol e traduzido para o Inglês. Concordância foi definida como $\geq 70 \%$ dos entrevistados. Resultados: Cinquenta participantes de 14 países responderam ao questionário. Para o tratamento médico de glaucoma, quase todas as respostas (98\% ou mais), confirmaram que o tratamento médico como terapia de primeira linha é preferido para a cirurgia, os análogos das prostaglandinas são os medicamentos de primeira escolha para o glaucoma primário de ângulo aberto (GPAA), a monitoração longitudinal eficácia deve incluir a pressão intraocular o estado estrutural e funcional além da qualidade de vida do paciente ser prejudicada pelo al to custo da medicação. Para a seção sobre o diagnóstico de glaucoma, todos os entrevistados confirmaram que, após análise inicial, a gonioscopia deve ser repetida ao longo do tempo, a perimetria automatizada padrão é o exame funcional mais importante para o diagnóstico e monitoramento do glaucoma primário de ângulo aberto, a espessura corneanacentral é importante na avaliação do glaucoma e exames de imagem computadorizados ajudam na avaliação clínica do disco óptico.

Conclusões: Este estudo mostra um alto nível de concordância na maioria dos aspectos do diagnóstico e tratamento de glaucoma entre os especialistas em glaucoma latino-americanos. Áreas de desacordo destacam a necessidade de novas evidências ou educação. Estes resultados serão úteis para orientar futuros esforços na otimização de práticas em relação ao glaucoma por médicos da América Latina.

Descritores: Glaucoma/diagnóstico; Glaucoma/tratamento; Questionários; Humanos

\section{INTRODUCTION}

It has been estimated that almost 5.7 million people in Latin America have glaucoma, principally the open-angle subtype, and that this number will increase to approximately 8 million people by
$2020^{(1)}$. The burden of glaucoma is substantial in Latin America, where it is one of the leading causes of blindness or visual impairment in both adults and children ${ }^{(2-9)}$ and has a significant negative impact on quality of life ${ }^{(10)}$. The burden of glaucoma may be higher in Latin
Study carried out at Headquarters of the Latin American Glaucoma Society - LAGS. Submitted for publication: February 15, 2013

Accepted for publication: March 20, 2013

${ }^{1}$ Physician, Hospital Oftalmologico Santa Lucia, Buenos Aires, Argentina.

Physician, Universidade Federal de São Paulo - UNIFESP - São Paulo, Brazil.

Physician, Universidade de São Paulo - USP - São Paulo, Brazil.

Physician, Hospital de Clinicas, School of Medicine, University of Buenos Aires, Buenos Aires,

Argentina.

Physician, Instituto de Glaucoma y Catarata, Lima, Peru.

${ }^{6}$ Physician, Hospital Universitario Austral, Buenos Aires, Argentina.
Funding: This survey was not sponsored.

Disclosure of potential conflicts of interest: D.E.Grigera has received payment from MSD for participating in an expert meeting, and has payment for lectures and received travel/accommodation support from Allergan and MSD. P.A.A.Mello has received payment for board membership, consultancy and grants from Alcon and Allergan; payment for lectures, manuscript preparation educational presentations and travel from Alcon, Allergan and Merck. W. Borbosa has received travel support from Allergan in relation to development of a paper; received payment for board membership from Allergan, payment for lectures from Alcon Laboratories and MSD. J. F.Casiraghi has received payment for board membership from MSD, Allergan and Poen; consultancy fees from Allergan, MSD, Pfizer, Peon, F Colon, Bausch and Lomb and HLB; payment for expert testimony from Allergan, Poen, F Colon and HLB; grants from Allergan; payment for lectures from, Allergan and Pfizer; payment for educational presentations from Allergan and Poen. R.P.Grossmann, None. A.Peyret has received payment for lectures from MSD; payment for manuscript preparation from Allergan; payment for educational presentations from Poen travel support from MSD.

Correspondence address: Daniel E Grigera. Universidad del Salvador. Marconi 920, 1636 - Olivos Buenos Aires, Argentina - E-mail: dgrigera2@fibertel.com.ar 
America than in more developed regions because poverty acts as a barrier to effective diagnosis and treatment ${ }^{(11,12)}$, resulting in a high proportion of patients presenting with advanced disease.

While diagnostic and treatment strategies for glaucoma have evolved over the years, many gaps remain in our understanding of optimal practice for diagnosis and management. Moreover, management practices differ between and even within countries, depending on the health infrastructure. Recently, attempts have been made by the World Glaucoma Association (WGA) to provide guidance on international best practices in glaucoma diagnosis and treatment. To this end, the WGA has developed a number of consensus statements, providing guidance on a range of issues including structure and function in the diagnosis of glaucoma ${ }^{(13)}$, closed-angle glaucoma (CAG), intraocular pressure (IOP), and medical therapy ${ }^{(14)}$.

Typically, consensus statements on glaucoma management practices have been developed by a restricted panel working in two phases: first surveying participants for their agreement on particular questions relating to clinical practice, and then meeting to share the results of the survey, before asking panelists to rate the questions again $^{(15,16)}$. However, considerable insight into the level of agreement among clinical experts can also be gained by administration of a single survey ${ }^{(17-19)}$, which can then guide the development of guidelines or highlight the need for further research or education on a national or regional basis.

The Latin American Glaucoma Society (LAGS) developed a survey among key clinical experts in the region to determine the level of agreement on key practices related to the treatment and diagnosis of glaucoma, including region-specific issues in Latin America. Here we report the methodology and findings of this research initiative.

\section{METHODS}

\section{QUESTIONNAIRE PREPARATION}

A multinational panel of ophthalmology experts developed a two-part questionnaire: Part 1 was on the medical treatment of glaucoma and Part 2 was on the diagnosis of glaucoma. The questionnaire consisted of a number of statements; respondents were asked to rate their agreement with each statement using various scales. The statements were developed by the panel based on an analysis of the medical literature, a review of existing WGA consensus statements, and their own clinical experience. Relevant medical literature was identified by means of a PubMed search undertaken in September 2009. The following search terms were used: treatment strategies, target IOP, general concepts about medical therapy, antiglaucoma drugs, adverse events, neuroprotection, compliance, specific aspects of treatment in Latin America and generic/copy medications, general aspects of glaucoma diagnosis, clinical examination of the optic nerve, examination of the nerve fiber layer, diagnosis in primary closed-angle glaucoma (PCAG), gonioscopy, functional examination, $I O P$, and structural examination by imaging. At the time of survey development, WGA consensus statements were available for diagnosis $^{(13)}$ and IOP, but not for glaucoma treatment.

The survey development panel drafted 107 statements relating to the medical therapy or diagnosis of glaucoma. The full results of the survey are presented in this paper (see Appendix). The questionnaire included open-ended and closed-ended questions (yes/ no, multiple choice, rating scale).

\section{SURVEY}

The survey was developed in Spanish, translated into English, and uploaded to an online survey tool. An email invitation to complete the survey was sent to 50 individuals from geographically diverse parts of the region: 31 were members of the LAGS and 19 were others who were identified by LAGS members as Latin American ophthalmologists with particular expertise in the field of glaucoma diagnosis and treatment. The survey was completed between October 2009 and April 2010.

\section{Analysis}

Upon receipt of the questionnaire results, the level of agreement or disagreement for each statement was calculated by assessing the percentage of respondents giving each answer. Consensus was defined a priori as agreement in $>70 \%$ of the group. For Likert scale questions, "strongly agree" and "agree", "strongly disagree" and "disagree" were pooled together. Combining scores for the purposes of categorization has been used in previous similar studies, in both glaucoma $^{(15,16)}$ and other indications ${ }^{(20)}$. Internal consistency for each part (medical treatment and diagnosis of glaucoma) and for each subcategory/topic, as well as overall consistency, was measured using a standardized Cronbach's coefficient alpha. A Cronbach's coefficient alpha of $\geq 0.65$ was considered to indicate internal consistency.

\section{RESULTS}

All 50 participants returned the survey and 48 participants completed all questions in the survey. Survey respondents were from Brazil $(n=16)$, Argentina ( $n=9)$, Colombia $(n=5)$, Mexico $(n=4)$, Chile $(n=3)$, Peru ( $n=3)$, Venezuela $(n=3)$, Costa Rica $(n=1)$, Guatemala $(n=1)$, Ecuador $(n=1)$, Paraguay $(n=1)$, Puerto Rico $(n=1)$, Uruguay $(n=1)$, and USA $(n=1)$. Most participants $(n=30)$ worked in both private practice and the public sector, but 17 worked solely in private practice and 1 solely in the public sector; 2 participants did not answer the question on clinical practice type. Survey respondents had been in clinical practice for between 2 and 50 years (mean \pm standard deviation [SD] $22.68 \pm 10.75$ years).

Overall, the panel found agreement in 75 (70.1\%) of 107 statements and no agreement in 32 (29.9\%) (Tables 1 and 2). We will now highlight the results of the survey; for full results, please refer to the Appendix. In Part 1, medical treatment of glaucoma, respondents unanimously agreed that knowing the hypotensive efficacy of different glaucoma medications was essential (question 15). Examples of medical therapy questions on which no agreement was reached were those related to achieving the greatest possible reduction in IOP (question 10), what constitutes the maximal number of medications (question 19), whether prostaglandin analogs reduce IOP in open-angle glaucoma (OAG) with peripheral anterior synechiae (question 25), the maximum number of daily doses to maintain patient adherence (question 37), and whether generic medications are bioequivalent and interchangeable (question 46).

In Part 2 on glaucoma diagnosis, respondents unanimously agreed on four issues: that after initial examination, gonioscopy should be performed in all patients with glaucoma or suspected glaucoma and repeated over time (questions 83 and 84), that standard automated perimetry (SAP) is the most important functional examination for the diagnosis and monitoring of primary open-angle glaucoma (POAG) (question 88), that central corneal thickness is important in the assessment of glaucoma or suspected glaucoma (question 92), and that computerized imaging helps in clinical evaluation of the optic disc (question 103). Examples of diagnostic questions where no agreement was reached were those relating to initial assessment of the optic nerve fiber layer (question 77), the most useful tonometric method to use in suspect glaucoma patients (question 98), use of the Pascal tonometer (question 95) or ocular response analyzer (ORA) (question 96) in preference to the Goldmann tonometer, tests for early detection of glaucoma damage (question 105), and optimal method of analyzing progression of nerve fiber layer (question 107).

Consistency scores for the full 107-question survey were 0.675619 for Part 1 on medical treatment of glaucoma, 0.640498 for Part 2 on diagnosis of glaucoma, and 0.675030 overall, indicating a general consistency in responses. 
Table 1. Medical treatment of glaucoma consensus statements (questions with $70 \%$ or greater agreement)

\begin{tabular}{|c|c|c|c|}
\hline $\begin{array}{l}\text { Question } \\
\text { № }\end{array}$ & $\begin{array}{l}\text { № of } \\
\text { responses }\end{array}$ & Summary & n (\%) \\
\hline \multicolumn{4}{|c|}{ Treatment strategies } \\
\hline 8 & 50 & Medical treatment is preferred first-line (over surgery) & $49(98.0 \%)$ \\
\hline \multicolumn{4}{|c|}{ Target intraocular pressure } \\
\hline 9 & 50 & Target IOP is a useful concept & $48(96.0 \%)$ \\
\hline 14 & 50 & Target IOP concept is dynamic and must be individualized & $48(96.0 \%)$ \\
\hline 11 & 50 & Target IOP must be determined for each patient & $48(96.0 \%)$ \\
\hline 12 & 50 & IOP should be at stable target levels for over 24 hours & $45(90.0 \%)$ \\
\hline 13 & 50 & Ideal medication decreases IOP, has minimal ocular side effects, and is affordable & $47(94.0 \%)$ \\
\hline \multicolumn{4}{|c|}{ General concepts } \\
\hline 15 & 50 & Knowledge of hypotensive efficacy of medication is essential & $50(100.0 \%)$ \\
\hline 18 & 50 & If hypotensive effect is $<10 \%$, medication is replaced with another & $44(88.0 \%)$ \\
\hline 21 & 50 & Medication of first choice for POAG is prostaglandin analogs & $49(98.0 \%)$ \\
\hline 16 & 50 & Longitudinal monitoring of efficacy should include IOP, structural and functional status & $49(98.0 \%)$ \\
\hline 17 & 50 & Hypotensive efficacy, with reasonable safety, is more important for choosing medication & $39(78.0 \%)$ \\
\hline 20 & 50 & Chronic use of benzalkonium chloride adversely affects prognosis for surgery & $47(94.0 \%)$ \\
\hline 24 & 50 & There are no significant clinical differences in hypotensive efficacy between different prostaglandin analogs & $38(76.0 \%)$ \\
\hline 26 & 50 & There are no significant clinical differences in hypotensive efficacy between different carbonic anhydrase inhibitors & $43(86.0 \%)$ \\
\hline 22 & 50 & Prostaglandin analogs have a significantly higher hypotensive efficacy than $\beta$-blockers & $50(100.0 \%)$ \\
\hline \multicolumn{4}{|c|}{ Adverse events } \\
\hline 31 & 50 & $\beta$-blockers have the best LOCAL safety profile & $42(84.0 \%)$ \\
\hline 32 & 50 & Prostaglandin analogs have the best SYSTEMIC safety profile & $45(90.0 \%)$ \\
\hline 27 & 50 & Hyperemia associated with the use of some glaucoma treatment medications is related to a mild inflammatory response & $36(72.0 \%)$ \\
\hline \multicolumn{4}{|c|}{ Neuroprotection } \\
\hline 33 & 50 & No systemic medication has a proven neuroprotective action in humans & $43(86.0 \%)$ \\
\hline 34 & 50 & No topical medication has a proven neuroprotective action in humans in addition to IOP lowering & $46(92.0 \%)$ \\
\hline \multicolumn{4}{|c|}{ Compliance } \\
\hline 39 & 50 & Quality of life is impaired by the high cost of medication & $48(96.0 \%)$ \\
\hline 35 & 50 & Lack of patient compliance is the main cause of glaucoma treatment failure & $37(74.0 \%)$ \\
\hline 36 & 50 & Compliance with medical therapy is a major impediment affecting approximately $50 \%$ of patients & $40(80.0 \%)$ \\
\hline 41 & 50 & Education for patients about their illness is critical for improving treatment compliance & $48(96.0 \%)$ \\
\hline \multicolumn{4}{|c|}{ Specific aspects of treatment in Latin America } \\
\hline 44 & 50 & I agree with the use of prostaglandin/timolol combinations in Latin America & $42(84.0 \%)$ \\
\hline 42 & 50 & Glaucoma therapy is unaffordable for most patients in Latin America & $36(72.0 \%)$ \\
\hline 45 & 50 & It is not important for prostaglandin/timolol combinations to be approved by the FDA & $35(70.0 \%)$ \\
\hline \multicolumn{4}{|c|}{ Generic/copy drugs } \\
\hline 47 & 49 & Copy medications are not bioequivalent and interchangeable & $40(81.6 \%)$ \\
\hline 50 & 49 & We as a group should be doing something about access to quality medical therapy & $47(95.9 \%)$ \\
\hline 51 & 49 & $\begin{array}{l}\text { I would participate in a multicenter comparative study of original medications versus generic/"copy" medications designed } \\
\text { by the LAGS }\end{array}$ & $46(93.9 \%)$ \\
\hline
\end{tabular}

FDA= Food and Drug Administration; IOP= intraocular pressure; LAGS= Latin American Glaucoma Society; POAG= primary open-angle glaucoma.

\section{DISCUSSION}

To our knowledge, this is the first region-wide survey of glaucoma diagnostic and treatment preferences among Latin American ophthalmologists. Our study has found a substantial level of agreement among glaucoma specialists in Latin America for most diagnostic and treatment practices surveyed.
Our survey found consistent agreement among regional specialists surveyed about the importance of treating to target IOP and maintaining a stable IOP over 24 hours, whereas the respondents did not agree that the greatest possible decrease in IOP should be sought in order to minimize the risk of progression of glaucoma damage. This implies that, among two possible strategies for optimizing medical 
Level of agreement among Latin American glaucoma subspecialists on the diagnosis and treatment of glaucoma:

RESULTS OF AN ONLINE SURVEY

Table 2. Diagnosis of glaucoma consensus statements (questions with $70 \%$ or greater agreement)

\begin{tabular}{|c|c|c|c|}
\hline $\begin{array}{l}\text { Question } \\
\text { № }\end{array}$ & $\begin{array}{l}\text { № of } \\
\text { responses }\end{array}$ & Summary & $\begin{array}{l}n(\%) \\
\text { responding in } \\
\text { the affirmative }\end{array}$ \\
\hline \multicolumn{4}{|c|}{ General concepts } \\
\hline 55 & 48 & Elevated IOP is not essential for diagnosis of POAG & $41(85.4 \%)$ \\
\hline 57 & 48 & Blood flow to the optic nerve is important in POAG pathogenesis & $35(72.9 \%)$ \\
\hline 52 & 48 & Structural and/or functional signs of damage are essential for diagnosis & $44(91.7 \%)$ \\
\hline 54 & 48 & Glaucoma diagnosis requires characteristic change to optic disc or visual field defect & $40(83.3 \%)$ \\
\hline 56 & 48 & Lack of defect in achromatic pathway is a requisite for pre-perimetric diagnosis & $38(79.2 \%)$ \\
\hline \multicolumn{4}{|c|}{ Clinical examination of the optic nerve } \\
\hline 67 & 48 & Advisable to estimate optic disc size biomicroscopically by slit lamp and/or direct ophthalmoscopy & $37(77.1 \%)$ \\
\hline 68 & 48 & Loss of shape of neuroretinal ring in normal-sized optic nerve heads is an early sign of glaucoma & $42(87.5 \%)$ \\
\hline 73 & 48 & $\begin{array}{l}\text { Clinical examination of the optic nerve should include disc size, keeping the ISNT rule, cup-disc ratio, asymmetry in the C-D } \\
\text { ratio, rim regularity, rim color and cupping, position of the blood vessels, presence of papillary and juxtapapillary hemorrhages, } \\
\text { peripapillary atrophy and conservation of the nerve fiber layer }\end{array}$ & $43(89.6 \%)$ \\
\hline 59 & 48 & $\begin{array}{l}\text { Clinical examination of optic nerve with dilated pupil in slit lamp using indirect magnification is the structural gold standard } \\
\text { for examining POAG }\end{array}$ & $44(91.7 \%)$ \\
\hline 60 & 48 & Recording the condition of the optic nerve is essential in glaucoma and suspected glaucoma & $46(95.8 \%)$ \\
\hline 61 & 48 & $\begin{array}{l}\text { Recording of optic nerve condition should be by color spectrophotography, digital photography and/or structural imaging, } \\
\text { with itemized drawing if other technologies are unavailable }\end{array}$ & $44(91.7 \%)$ \\
\hline 62 & 48 & Photographic documentation is the gold standard for structural evaluation in glaucoma & $43(89.6 \%)$ \\
\hline 63 & 48 & Serial photography is the basic minimum structural method of recording progression in POAG & $45(93.8 \%)$ \\
\hline 64 & 48 & Examination with indirect vision lenses $(90,78$, and 60 diopters) is suitable for clinical evaluation of optic nerve & $45(93.8 \%)$ \\
\hline 72 & 48 & Increase with time in area of cupping or cup-disc ratio is important in differentiating normal nerve and glaucoma & $47(97.9 \%)$ \\
\hline 74 & 48 & It is advisable to examine the optic nerve's condition in glaucoma patients at each visit & $36(75.0 \%)$ \\
\hline 58 & 48 & An optic nerve examination is essential for the diagnosis and management of glaucoma & $45(93.7 \%)$ \\
\hline 65 & 48 & $\begin{array}{l}\text { Lenses with higher dioptric power }(90 \mathrm{D}) \text { provide satisfactory viewing in almost all pupil sizes, while the smaller ones, especially } \\
\text { that of } 60 \mathrm{D} \text {, require mydriasis, or at least that the pupil diameter not be reduced. The latter, however, provide a better view } \\
\text { of the details of the optic nerve }\end{array}$ & $37(77.1 \%)$ \\
\hline 69 & 48 & $\begin{array}{l}\text { Optic disc hemorrhages indicate the presence of glaucoma damage and suggest progression, and are most frequently found } \\
\text { in normal tension glaucoma }\end{array}$ & $44(91.6 \%)$ \\
\hline 70 & 48 & Early or moderate optic nerve damage can be underestimated in small optical nerves, and a proper diagnosis may not be made & $48(100.0 \%)$ \\
\hline 71 & 48 & In large optic nerves, the diagnosis of glaucoma is often overestimated & $46(95.9 \%)$ \\
\hline \multicolumn{4}{|c|}{ Examination of the nerve fiber layer } \\
\hline 75 & 48 & Monitoring the condition of the nerve fiber layer in glaucoma is essential & $35(72.9 \%)$ \\
\hline 76 & 48 & $\begin{array}{l}\text { Diffuse defects of the nerve fiber layer in OAG are harder to detect than localized defects and are inferred by detailed obser- } \\
\text { vation of the vessels }\end{array}$ & $47(97.9 \%)$ \\
\hline 78 & 46 & Localized defects of the nerve fiber layer are arch-shaped and extend to the edge of the optic disc & $41(85.4 \%)$ \\
\hline \multicolumn{4}{|c|}{ Diagnosis in PCAG/gonioscopy } \\
\hline 84 & 48 & After the initial examination, gonioscopy should be repeated over time & $48(100.0 \%)$ \\
\hline 82 & 48 & Gonioscopic evaluation is recommended as part of routine eye exam for all patients aged $>40$ years & $34(70.8 \%)$ \\
\hline 85 & 48 & It is useful to adopt a particular gonioscopic-type classification of angle & $37(77.1 \%)$ \\
\hline 80 & 48 & Van Herick's technique for estimating anterior chamber depth is not a substitute for gonioscopy & $45(93.8 \%)$ \\
\hline 83 & 48 & Gonioscopy should be performed in all patients with glaucoma or suspected glaucoma & $48(100.0 \%)$ \\
\hline \multicolumn{4}{|c|}{ Functional examination } \\
\hline 88 & 48 & SAP is the most important functional examination for diagnosis and monitoring of POAG & $48(100.0 \%)$ \\
\hline 90 & 48 & $\begin{array}{l}\text { Both frequency doubling perimetry and blue on yellow perimetry are useful in detecting functional defects before achromatic } \\
\text { perimetry is used }\end{array}$ & $39(81.3 \%)$ \\
\hline 102 & 48 & The FDT should be utilized in a glaucoma suspect with normal SAP & $37(77.1 \%)$ \\
\hline 87 & 48 & The computerized perimetry examination is essential for the diagnosis of POAG & $35(72.9 \%)$ \\
\hline 89 & 48 & A multimodal functional assessment (not perimetry techniques) seems to be most effective in detecting early glaucoma defects & $39(81.3 \%)$ \\
\hline 91 & 48 & The functional changes in glaucoma are progressive visual field deterioration and loss of sensitivity to colors & $45(93.8 \%)$ \\
\hline
\end{tabular}


Table 2. Diagnosis of glaucoma consensus statements (questions with $70 \%$ or greater agreement) (continued)

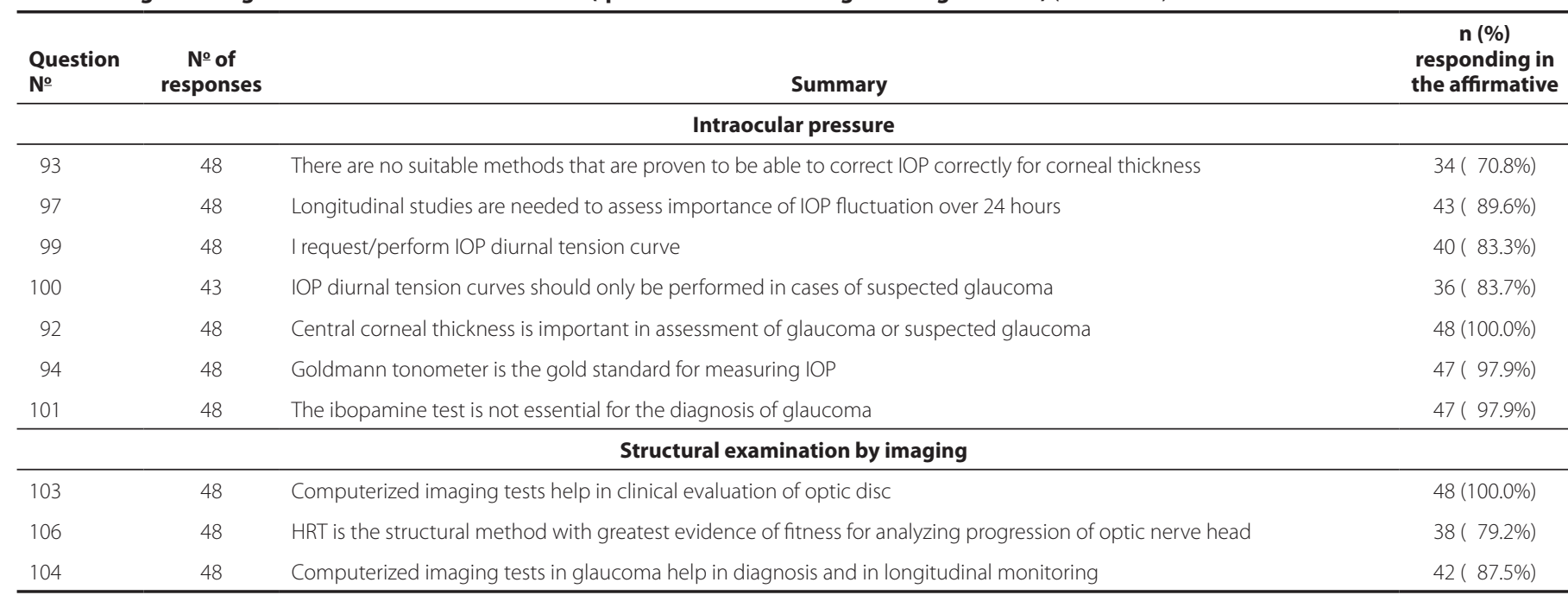

FDT = frequency doubling technology; $I O P=$ intraocular pressure; $I S N T=$ inferior $\geq$ superior $\geq$ nasal $\geq$ temporal; HRT= Heidelberg retinal tomography; OAG= open-angle glaucoma; $P C A G=$ primary closed-angle glaucoma; $\mathrm{POAG}=$ primary open-angle glaucoma; $\mathrm{SAP}=$ standard automated perimetry.

therapy (using target IOP or searching for the lowest possible IOP with initial medication), the responders clearly preferred the first one. Using target IOP to guide clinical management is a well-established practice and one that is supported by the results of large-scale studies such as the Collaborative Initial Glaucoma Treatment Study $(\mathrm{CIGTS})^{(21)}$. This approach allows treatment to be targeted to the individual's baseline IOP, optic nerve appearance and visual function, and to initiate more aggressive treatment at signs of deterioration. It also allows physicians and patients to develop a partnership in glaucoma management; if patients are aware of the target IOP they are trying to reach, they may be more engaged and adherent with treatment. While there is clear evidence that the lower the IOP, the less the risk of glaucomatous progression, physicians may be reluctant to initiate aggressive therapy because this may limit their future treatment options. Physicians may also fear that patients will develop adverse effects, potentially impacting their adherence. For some patients, the aggressive therapeutic options (combination therapy or surgery) may be unaffordable, particularly in developing countries. These factors probably contributed to the lack of agreement about achieving the greatest possible reduction in IOP in our survey.

Some statements in our survey have important educational implications. For example, the panelists consider it essential for a clinician to know the rates of hypotensive efficacy of glaucoma medications. They also agreed that a hypotensive effect of less than $10 \%$ is unacceptable and should prompt substitution with a more effective treatment.

It is also interesting to note that, in a region known historically to favor low-cost medications such as $\beta$-blockers, the Latin American glaucoma specialists in our sample considered prostaglandin analogs to be the monotherapy of first choice. This probably reflects the respondents'assessment of drug efficacy and safety rather than affordability, since there was agreement that the cost of medical therapy is not affordable for most patients in Latin America (question 42). Prostaglandin analogs have demonstrated greater hypotensive efficacy compared with other classes of topical glaucoma therapies ${ }^{(22,23)}$ and a low rate of systemic adverse effects, a fact with which the Latin American respondents to our survey also showed substantive agreement. The most common adverse event with prostaglandin analogs is conjunctival hyperemia, whereas this is less frequent with topical $\beta$-blockers ${ }^{(24)}$. Latin American physicians agree that topical $\beta$-blockers have the best ocular safety profile (question 31 ). Overall, respondents believe that hypotensive efficacy with reasonable safety is more important than safety alone (question 17). Therefore, taken together, the survey findings indicate that Latin American physicians consider that the greater efficacy of prostaglandin analogs and their improved systemic safety profile outweigh concerns about ocular tolerability. Agreement was not reached regarding the number of bottles that constitute maximum medical therapy, or on the maximum number of instillations compatible with good cooperation with the treatment. Presumably, this reflects the diversity of adherence behavior between patients seen in routine clinical practice.

In our survey, most respondents (70.0\%) did not think it was important that certain medications (like a fixed combination of prostaglandin analog plus $\beta$-blocker) have not been approved by the US Food and Drug Administration (FDA). This may indicate an acceptance of lower standards of rigor in the regulation of pharmaceutical products in Latin America compared with the US. While many survey respondents agreed (59.2\%) that generic medications were bioequivalent and interchangeable, they also agreed (81.6\%) that "copy medications" were not. The World Bank has suggested that Latin American regulatory agencies are under-resourced, and has highlighted differences between countries in both registration policies and terminology (including the use of the terms "generic" and "bioequivalence") ${ }^{(25,26)}$. This may have led to different interpretations of the questions relating to generic medications in our survey between respondents from different countries, and contributed to the lack of agreement about the bioequivalence of generic and "copy" medications (questions 46 and 47).

Regarding the diagnosis of glaucoma, Latin American physicians agreed on the need to examine the condition of the optic nerve at each visit, consistent with WGA recommendations ${ }^{(13)}$. However, this may be an area in which theory falls short of practice, since there are data to suggest that, even in developed countries, optic nerve status examination and documentation are suboptimal during routine clinical practice ${ }^{(27,28)}$. Our survey also found agreement on photographic documentation as the gold standard for structural evaluation in glaucoma and the value of computerized imaging in the evaluation of the optic disc. These approaches are also consistent with WGA consensus recommendations ${ }^{(13)}$, and can produce more accurate and quantitative assessment of structural changes than can be achieved with annotated drawings or written chart entries ${ }^{(29)}$. Nevertheless, Latin American survey participants agreed that an itemized drawing can be a useful resource when technology is unavailable. 
Latin American physicians agreed on the importance of gonioscopy in first examination for all patients over 40 years to detect the presence of CAG, and its repetition over time when examining a CAG patient or a CAG suspect. Direct epidemiologic data on prevalence of CAG in Latin America are limited. They range from a general estimation of $5.7 \%$ of glaucoma cases ${ }^{(1)}$ to $21.4 \%$ in one sample from South Brazil $^{(30)}$. Unpublished surveys indicate that CAG rates may be high in some native ethnic populations within Latin America.

Not surprisingly, no agreement was obtained on the new methods of tonometry such as the Pascal dynamic contour tonometer or the ORA. This may reflect a concern among Latin American physicians that more published evidence and clinical experience with these devices are required. However, there was agreement about the importance of measuring central corneal thickness in order to gain a more accurate assessment of IOP.

A limitation of the present research is that the 107 items in the survey could not cover all the issues involving diagnosis and treatment of glaucoma. Although we created the questionnaire based on a detailed review of the literature, there may have been other relevant topics that were not included. Further investigation, possibly including the distribution of a second questionnaire to experts in this field, may be needed for further validation. Such a survey could also identify any changes over time in the opinions of Latin American ophthalmologists toward optimal practice in the diagnosis and management of glaucoma.

\section{CONCLUSION}

This survey, the largest one to date on diagnosis and therapy of glaucoma among Latin American experts, has demonstrated a high level of agreement on optimal practices in the diagnosis and medical management of glaucoma. There was consensus for more than twothirds of the questions, indicating a high level of agreement across the region on evidence-based recommendations. However, many barriers toward optimal detection and treatment of glaucoma exist in Latin America. The information gained from this survey can be used to inform future educational efforts in the region, with the aim of further improving glaucoma diagnosis and management.

\section{ACKNOWLEDGMENTS}

The following individuals have participated as part of the "LAGS Plus Survey Panel" in the development of this survey: Alvaro Abelenda (Uruguay), Jorge Acosta (Argentina), John Jairo Aristizábal (Colombia), Paulo A. Arruda Mello (Brazil), George Arzeno (Puerto Rico, USA), Marcos Boissiere (Venezuela), Héctor Borel (Chile), Javier Casiraghi (Argentina), Rosendo Castellanos (Venezuela), Carlos Luis Chacón (Ecuador), Ralph Cohen (Brazil), Javier Córdoba Umana (Costa Rica), Sebastiao Cronemberger (Brazil), Felicio da Silva (Brazil), Geraldo Vicente de Almeida (Brazil), María Fernanda Delgado (Colombia), Mauricio Della Paolera (Brazil), José Di Martino (Paraguay), Juan Dios (Peru), Héctor Fontana (Argentina), Mara Fontes (Brazil), Alfonso García López (Mexico), Fernando Gómez Goyeneche (Colombia), Alejandro Gonella (Argentina), Marcos Geria (Argentina), Daniel Grigera (Argentina), Curt Hartleben (Mexico), Jesús Jiménez Román (Mexico), Fabián Lerner (Argentina), Eugenio Maul (Chile), Felipe Medeiros (USA), Juan José Mura (Chile), Carlos Akira Omi (Brazil), Marcelo Palis Ventura (Brazil), Augusto Paranhos (Brazil), Juan Camilo Parra (Colombia), Rodolfo Pérez Grossmann (Peru), Joao Antonio Prata Jr (Brazil), Alejo Peyret (Argentina), Juan Carlos Rueda (Colombia), Lisandro Sakata (Brazil), Walter Schieber (Guatemala), Remo Susanna Jr (Brazil), Iván Maynart Tavares (Brazil), Enrique Vargas (Peru), Roberto Murad Vessani (Brazil), Juan Vieira (Venezuela), Riuitiro Yamane (Brazil), and Jaime I. Yankelevich (Argentina).

Dr Grigera organized and ran the survey. Statistics were calculated for internal consistency alpha by Lori A. Christman at STATKING
Clinical Services; this work was funded by ACUMED. Editorial/medical writing support was provided by G Devgan at ACUMED (New York, NY, USA) and was funded by Pfizer Inc.

\section{REFERENCES}

1. Quigley HA, Broman AT. The number of people with glaucoma worldwide in 2010 and 2020. Br J Ophthalmol. 2006;90(3):262-7. Comment in: Br J Ophthalmol. 2006; 90(3):253-4.

2. Arieta CE, de Oliveira DF, Lupinacci AP, Novaes P, Paccola M, Jose NK, et al. Cataract remains an important cause of blindness in Campinas, Brazil. Ophthalmic Epidemiol. 2009;16(1):58-63.

3. Cass H, Landers J, Benitez P. Causes of blindness among hospital outpatients in Ecuador. Clin Exper Ophthalmol. 2006;34(2):146-51.

4. Eduardo Leite Arieta C, Nicolini Delgado AM, Jose NK, Temporini ER, Alves MR, de Carvalho Moreira Filho D. Refractive errors and cataract as causes of visual impairment in Brazil. Ophthal Epidemiol. 2003;10(1):15-22.

5. Gilbert CE, Canovas R, Hagan M, Rao S, Foster A. Causes of childhood blindness: results from west Africa, south India and Chile. Eye (Lond). 1993;7(Pt 1):184-8.

6. Haddad MA, Sei M, Sampaio MW, Kara-Jose N. Causes of visual impairment in children: a study of 3,210 cases. J Pediatr Ophthalmol Strabismus. 2007:44(4):232-40.

7. Salomão SR, Mitsuhiro MR, Belfort Jr R. Visual impairment and blindness: an overview of prevalence and causes in Brazil. An Acad Bras Cienc. 2009;81(3):539-49.

8. Silva AM, Matos MH, Lima Hde C. [Low vision service at the Instituto Brasileiro de Oftalmologia e Prevencao da Cegueira (IBOPC): analysis of the patients examined on the first year of the department (2004)]. Arq Bras Oftalmol. 2010;73(3):266-70. Portuguese.

9. Munoz B, West SK. Blindness and visual impairment in the Americas and the Caribbean Br J Ophthalmol. 2002;86(5):498-504.

10. Cypel MC, Kasahara N, Atique D, Umbelino CC, Alcântara MP, Seixas FS, et al. Quality of life in patients with glaucoma who live in a developing country. Int Ophthalmol. 2004;25(5-6):267-72

11. Fraser S, Bunce C, Wormald R, Brunner E. Deprivation and late presentation of glaucoma: case-control study. BMJ. 2001;322(7287):639-43. Comment in: BMJ. 2001; 323(7303):47.

12. Ramalho CM, Ribeiro LN, Olivieri LS, Silva JA, Vale TC, Duque W de P. [Socioeconomic profile of individuals presenting with glaucoma in the service of ophthalmology of the University Hospital of the Federal University of Juiz de Fora - Minas Gerais - Brazil] Arq Bras Oftalmol. 2007;70(5):809-13. Portuguese.

13. Weinreb RN, Greve EL. Glaucoma diagnosis: structure and function. Amsterdam, The Netherlands: Kugler Publications; 2004. (WGA Consensus Series 1).

14. Weinreb RN, Liebmann J. Medical treatment of glaucoma. Amsterdam, The Netherlands: Kugler Publications; 2010. (WGA Consensus Series 7)

15. Lee PP, Sultan MB, Grunden JW, Cioffi GA; IOP Consensus Panel. Assessing the importance of IOP variables in glaucoma using a modified Delphi process. J Glaucoma. 2008;19(5):281-7.

16. Wilson MR, Lee PP, Weinreb RN, Lee BL, Singh K; Glaucoma Modified RAND-Like Methodology Group. A panel assessment of glaucoma management: modification of existing RAND-like methodology for consensus in ophthalmology. Part I: Methodology and design. Am J Ophthalmol. 2008;145(3):570-4.

17. Gaskin BJ, Carroll SC, Gamble G, Goldberg I, Danesh-Meyer HV. Glaucoma management trends in Australia and New Zealand. Clin Exper Ophthalmol. 2006;34(3):208-12.

18. Sheth HG, Goel R, Jain S. UK national survey of prophylactic YAG iridotomy. Eye (Lond) 2005;19(9):981-4.

19. Vaideanu D, Fraser S. Glaucoma management in pregnancy: a questionnaire survey Eye (Lond). 2007;21(3):341-3.

20. Upton J, McCutcheon E, Loveridge C, Wiggins J, Walker S, Fletcher M. What provokes experienced COPD clinical practitioners in the UK to initiate or change medication? A consensus study. Prim Care Respir J. 2011;20(2):155-60. Comment in: Prim Care Respir J. 2011;20(2):111-2.

21. Lichter PR, Musch DC, Gillespie BW, Guire KE, Janz NK, Wren PA, Mills RP; CIGTS Study Group. Interim clinical outcomes in the Collaborative Initial Glaucoma Treatment Study comparing initial treatment randomized to medications or surgery. Ophthalmology. 2001;108(11):1943-53. Comment in: Ophthalmology. 2003; 110(2):249; author reply 249. Ophthalmology. 2001;108(11):1939-40. Ophthalmology. 2003;110(2):249; author reply 249-50. Ophthalmology. 2003; 110(2):249; author reply 249-50

22. Stewart WC, Konstas AG, Nelson LA, Kruft B. Meta-analysis of 24-hour intraocular pressure studies evaluating the efficacy of glaucoma medicines. Ophthalmology. 2008;115(7):1117.e1-1122.e1. Comment in: Ophthalmology. 2009;116(7):1416-7; author reply 1417. Ophthalmology. 2009;116(7):1418; author reply 1418-9.

23. van der Valk R, Webers CA, Schouten JS, Zeegers MP, Hendrikse F, Prins MH. Intraocular pressure-lowering effects of all commonly used glaucoma drugs: a meta-analysis of randomized clinical trials. Ophthalmology. 2005;112(7):1177-85.

24. Servat JJ, Bernardino CR. Effects of common topical antiglaucoma medications on the ocular surface, eyelids and periorbital tissue. Drugs Aging. 2011;28(4):267-82. 
25. Homedes N, Lopez Linares R, Ugalde A. Generic drug policies in Latin America. Health, Nutrition and Population (HNP) Discussion Paper. Washington DC: The World Bank: 2005.

26. Homedes N, Ugalde A. Multisource drug policies in Latin America: survey of 10 countries. Bull World Hralth Organ. 2005;83(1):64-70.

27. Fremont AM, Lee PP, Mangione CM, Kapur K, Adams JL, Wickstrom SL, et al. Patterns of care for open-angle glaucoma in managed care. Arch Ophthalmol. 2003;121(6): $777-83$.
28. Hertzog LH, Albrecht KG, LaBree L, Lee PP. Glaucoma care and conformance with preferred practice patterns. Examination of the private, community-based ophthalmologist. Ophthalmology. 1996;103(7):1009-13.

29. Greenfield DS, Weinreb RN. Role of optic nerve imaging in glaucoma clinical practice and clinical trials. Am J Ophthalmol. 2008;145(4):598-603.

30. Sakata K, Sakata LM, Sakata VM, Santini C, Hopker LM, Bernardes R, et al. Prevalence of glaucoma in a South Brazilian population: Projeto Glaucoma. Investig Ophthalmol Vis Sci. 2007:48(11):4974-9. 